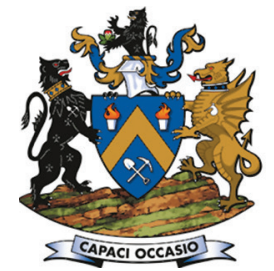

\title{
Evaluation of spheroidized tungsten carbide powder produced by induction plasma melting
}

\author{
R.M. Dire' ${ }^{1}$ H. Bissett ${ }^{2}$, D. Delport ${ }^{1}$, and K. Premlall ${ }^{1}$
}

Affiliation:

1 Tshwane University of Technology, Pretoria West, Pretoria, South Africa.

2 The South African Nuclear Energy Corporation SOC Ltd. (Necsa), North West Province, South Africa.

Correspondence to:

H. Bissett

Email:

hertzog.bissett@necsa.co.za

Dates:

Received: 1 Sep. 2020

Revised: 27 May 2021

Accepted: 27 May 2021

Published: April 2021

\section{How to cite:}

Dire, R.M., Bissett, H.,

Delport, D., and Premlall, K. 2021

Evaluation of spheroidized tungsten carbide powder produced by induction plasma melting.

Journal of the Southern African Institute of Mining and Metallurgy, vol. 121, no. 4, pp. 175-180.

DOI ID:

http://dx.doi.org/10.17159/24119717/1352/2021

ORCID

R.M. Dire

https://orchid.org/0000-0003-

3107-3571

H. Bissett

https://orchid.org/0000-00031034-7801

\section{Synopsis}

Tungsten carbide is a fine grey powder. It can be formed into shapes by compacting with the addition of a binder. Spherical particles are generally preferred in additive manufacturing as they pack together more efficiently than non-spherical particles, promoting a uniform powder bed density, better flowability, and elimination of internal cavities and fractures, resulting in a better quality of final product. The particle shape of powders can be transformed into spherical through the process of spheroidization. However, due to its high melting point, tungsten carbide could be difficult to spheroidize.

Tungsten carbide was spheroidized using an inductively coupled radio frequency plasma at various plate powers between 9 and $15 \mathrm{~kW}$. The influence of additional $\mathrm{H}_{2}$ in the sheath gas on the chemical composition of the tungsten carbide product was also investigated by means of XRD, which indicated that WC is converted to $\mathrm{W}_{2} \mathrm{C}$ at higher $\mathrm{H}_{2}$ concentrations. Optical analysis of SEM micrographs indicated that the spheroidization ratio increased with increased plasma energy.

\section{Keywords}

spheroidization, induction plasma melting, tungsten carbide.

\section{Introduction}

Tungsten carbide is a chemical compound used for various high-temperature applications. In its most basic form, tungsten carbide is a fine grey powder, which can be compacted with the addition of a binder (Co) and formed into shapes by a sintering process for use in industrial machinery, cutting tools, abrasives, armour-piercing shells, and jewellery (Pohanish, 2012).

Carbides are one of the most interesting groups of materials in that they exhibit unique properties such as high chemical stability, low thermal expansion, high thermal conductivity, and high temperature resistance. Among the several carbide synthesis methods, carbothermic reduction is the most preferred technique in industry, as it allows the use of a wide range of materials as precursor (Devečerski, 2011). Carbothermic reaction involves the reduction of substances, often metal oxides $\left(\mathrm{MO}_{\mathrm{x}}\right)$, using carbon as the reducing agent (Earnshaw, and Greenwood, 1997) and reducing metal oxide nanoparticles to metallic elements in the presence of carbon by heat treatment in an inert atmosphere. The metallic element then reacts with the excess carbon to form a carbide (Barker, Swoyer, and Saidi, 2003).

Tungsten carbide is extremely hard, and its surface resists impacts, scratches, and abrasion. It is almost as dense as gold, so tungsten carbide rings have a satisfying 'heft' when worn (Haynes, 2011). Some of the objects made from tungsten carbide can be manufactured through the additive manufacturing (AM) process, which is a fast-emerging technology in which a shape is fabricated using layer-by-layer deposition of a material in a bottom-up manufacturing method, allowing for the fabrication of three-dimensional (3D) parts with complex geometrical features that are difficult to manufacture using traditional machining techniques (Guo and Leu, 2013).

The most important powder characteristics to consider for AM include: particle size, shape, density, porosity, surface area, and topography. Spherical powders are generally preferred as they pack together more efficiently than non-spherical particles, giving uniform powder bed density, better flowability (do not clog machinery), and result in higher quality of final products. The particle shape of powders can be transformed into spherical by the process of spheroidization. Spheroidization refers to heat treatment and/or a modification process that is used to convert granular shapes to spheroidal shapes (Hillert, 1962). 


\section{Evaluation of spheroidized tungsten carbide powder produced by induction plasma melting}

There is a need in industry to convert angular shaped powders into spherical shaped powders. The following benefits would result from the spheroidization process: improved powder flowability, increased packing density, elimination of internal cavities and fractures, changing the surface morphology of the particles, and increasing the chemical purity (Hillert, 1962).

Entities such as the National Laser Centre (NLC) at the CSIR uses tungsten carbide for thermal coating on various materials. Methods such as thermal spraying require spherical particles to ensure effective splat formation on the substrate or surface being coated.

The South African Nuclear Energy Corporation SOC Ltd. (Necsa) has obtained a $15 \mathrm{~kW}$ inductively coupled radiofrequency (RF) thermal plasma system from Tekna Plasma Systems Inc., which is used for the spheroidization of various powders. The focus of this study is the spheroidization of irregularly-shaped pure tungsten carbide powder to investigate the capabilities of the plasma system. Spheroidization of powders should result in a spheroidization ratio as close as possible to $100 \%$, while minimizing the fraction of material evaporated.

\section{Radio frequency (RF) plasma spheroidisation}

Plasma is classified as the fourth state of matter. Thermal plasmas can have very high temperatures based on the electron temperatures or densities. The temperature of the plasma is determined by the kinetic energies of the heavy particles such as the ions, atoms, or molecules (Haehn et al., 1986).

Currently, methods such as inductively coupled RF plasma spheroidization and water atomization can be used to form spherical particles. However, most of the methods are not able to produce spherical tungsten carbide powders due to its high melting point $\left(2870^{\circ} \mathrm{C}\right)$ (Ku et al., 2019). The RF plasma method is an exception. This process can be used to prepare powders having high sphericity with minimum contamination, as the materials are not in contact with refractories and no impurities are added as a result of electrode evaporation (Kwak, 2010; Tong, 2015). Plasma spheroidization can manufacture spherical powder particles which have a uniform composition, high sphericity, and excellent flowability (Lu, Zhu, and Zhang, 2012).

A schematic representation of the Tekna $15 \mathrm{~kW}$ induction plasma system is shown in Figure 1. This particular RF plasma system uses a PL-35M induction torch which can operate between 2 and $5 \mathrm{MHz}$ (radio-frequency range). In this study the PL-35M torch was mounted on a reactor chamber equipped with a 'catch pot' for the collection of the spheroidized tungsten carbide powder.

The irregular-shaped feed powder was introduced into the plasma torch through a water-cooled probe with the assistance of an inert carrier gas (Ar). Inside the plasma 'flame' the particles were rapidly melted, followed by rapid cooling to form spherical particles. Fine particles were formed due to evaporation, followed by condensation. These particles were collected in the cyclone and filter sections of the system, as shown in Figure 1. The plasma gases used were $\mathrm{Ar}$ or $\mathrm{Ar} / \mathrm{H}_{2}$.

\section{Experimental}

The tungsten carbide powder used in the experiment was a mixture of $\mathrm{WC}$ and $\mathrm{W}_{2} \mathrm{C}$. The as-received powder was sieved into various fractions using a sieve shaker. Only the sieve fraction 45-75 $\mu \mathrm{m}$ was used in this study.

\section{Spheroidization ratio, fraction of evaporation, particle density, and particle size distribution}

The powder was plasma treated at various conditions as indicated in Table I. For all experiments the central and sheath gas flow rates were kept constant. The powder feed rate was

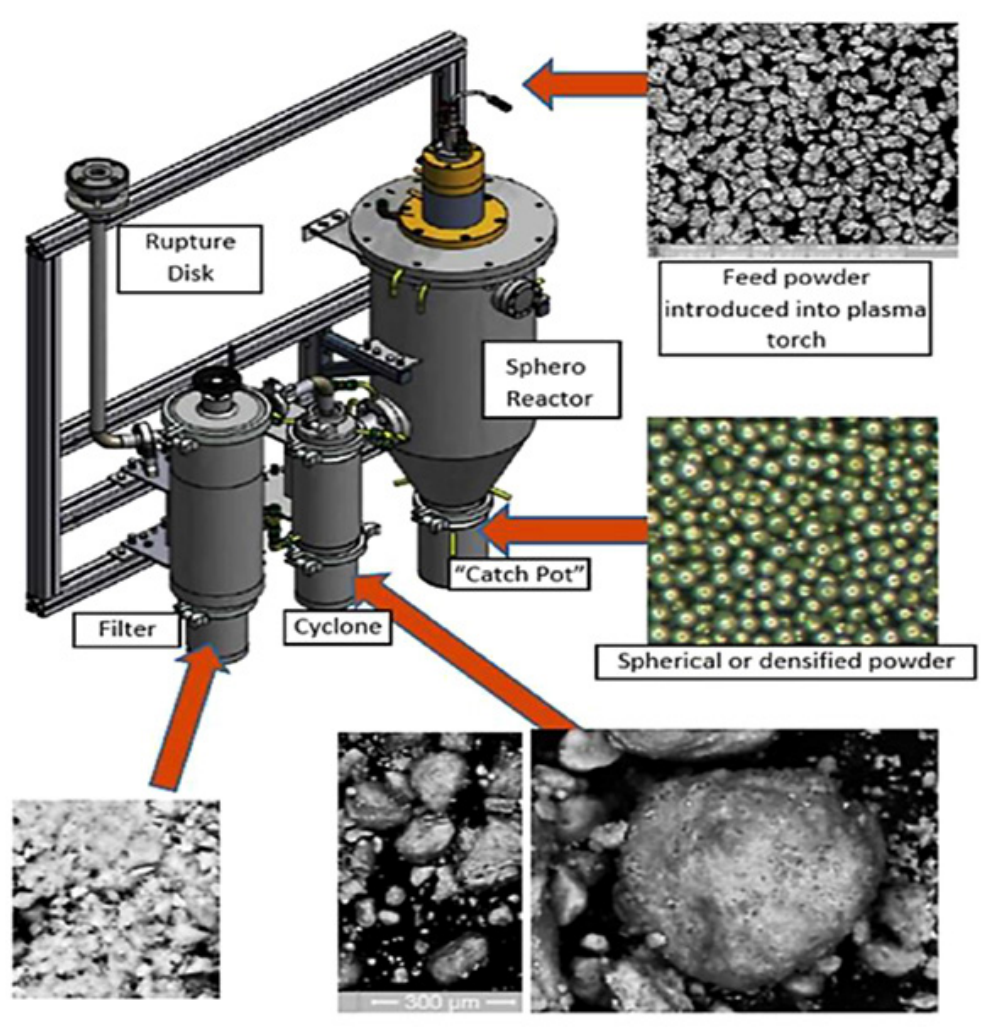

Figure 1-Schematic representation of the $15 \mathrm{~kW}$ Tekna spheroidization system 


\section{Evaluation of spheroidized tungsten carbide powder produced by induction plasma melting}

approximately $0.7 \mathrm{~kg} / \mathrm{h}$, reactor pressure was $85 \mathrm{kPa}$ (abs.), and the carrier gas (Ar) flow rate was 2 standard litres per minute (slpm).

After spheroidization, the collected powders were weighed in order to determine the evaporated fraction of the powder (condensed as very fine particles $<<150 \mathrm{~nm}$ ).

SEM analyses of the densified powders were performed using a Quanta FEI 200 D SEM system. Image processing was applied on the backscattered electron (BSE) images. The Carl Zeiss Zen 2 Core software package was used to determine whether there was a quantifiable change in the particle morphology under different conditions. The average circularity was determined by evaluating a number of particles and making use of Equation [1]. The shape factor $f_{\text {circ }}$ is the circularity, a function of the perimeter $P$ and the area $A$ :

$$
f_{\text {circ }}=\frac{4 \pi A}{P^{2}}
$$

In this instance the circularity varies between unity and nearzero, with the circularity of a circle equal to 1 . Spheroidization should result in an increased circularity when compared to the irregularly shaped feed powder.

The feed and the plasma-treated powders were also characterized according to density, using an AccuPyc II 1340 gas displacement helium pycnometer. The $10 \mathrm{~cm}^{3}$ sample cup was used for density analysis of three samples to determine the average density. Particle size distributions (PSDs) of all powders were determined using a Saturn DigiSizer II analyser.
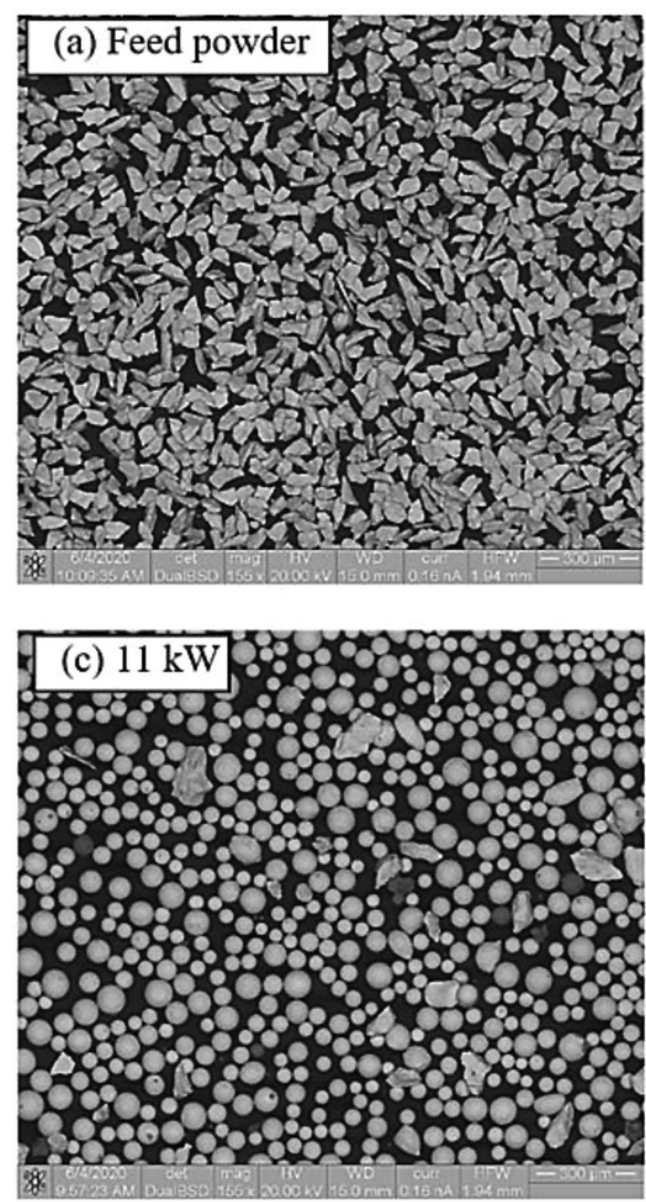

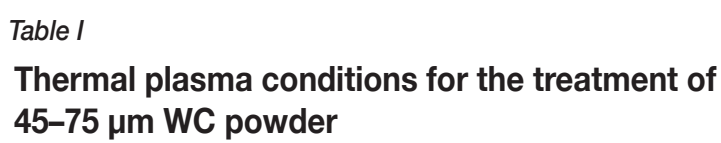

Thermal plasma conditions for the treatment of 45-75 $\mu \mathrm{m}$ WC powder

\begin{tabular}{|l|c|c|}
\hline $\begin{array}{l}\text { Plasma plate } \\
\text { power (kW) }\end{array}$ & $\begin{array}{c}\text { Hydrogen concentration } \\
\text { in plasma (\% v/v) }\end{array}$ & $\begin{array}{c}\text { Energy consumption } \\
\text { (kW.h/kg) }\end{array}$ \\
\hline 9 & 0.00 & 10.98 \\
11 & 0.04 & 13.58 \\
15 & 0.08 & 20.00 \\
\hline
\end{tabular}

\section{Phase composition}

Phase composition of the powders was determined by X-ray diffraction (XRD) using a Bruker D8 Advance diffractometer equipped with a $\mathrm{Cu} \mathrm{K} \alpha(\lambda=0.15418 \mathrm{~nm})$ radiation source. Data was collected using a LynxEye position-sensitive detector. The phases were identified using ICDD's PDF4+ 2020 version database. The phase compositions were determined by Rietveld refinement.

\section{Results and discussion}

Figure 2 shows the SEM BSE images of the feed and plasmatreated powders. The feed powder was irregularly-shaped and spheroidization of the powder had occurred at higher (11 and $15 \mathrm{~kW}$ ) plasma plate powers and higher $\mathrm{H}_{2}$ concentrations $(0.04$ and $0.08 \% \mathrm{v} / \mathrm{v}$ ).
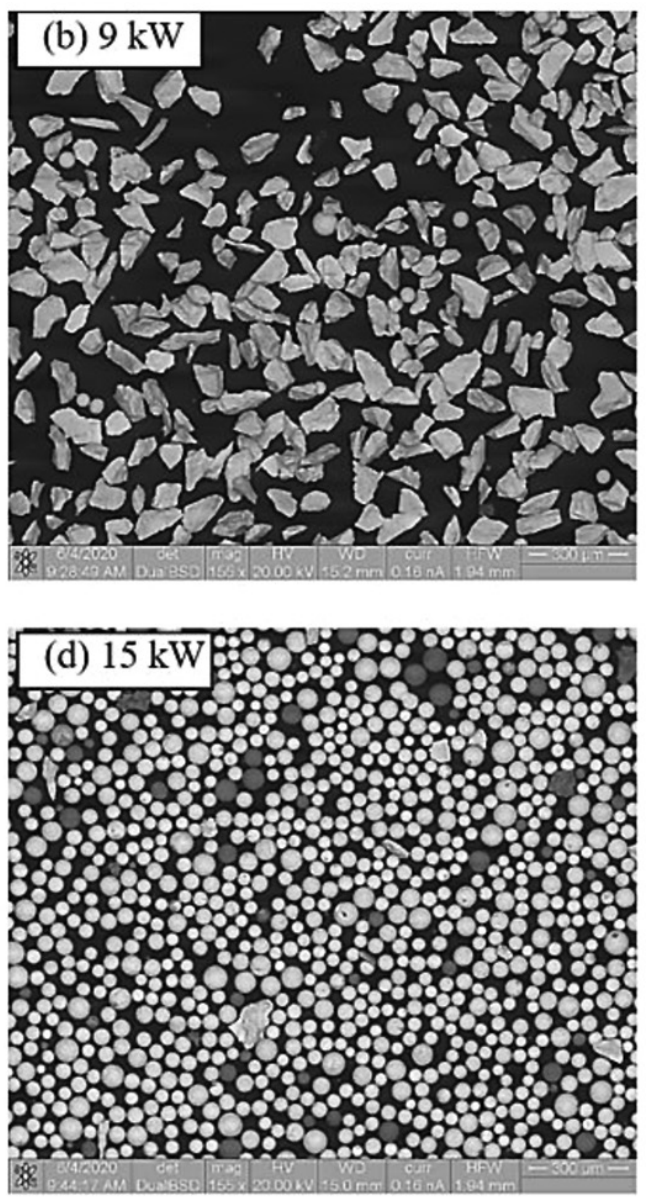

Figure 2-SEM-BSE images at 155x magnification of the (a) tungsten carbide 45-75 $\mu \mathrm{m}$ feed powder and powders plasma-treated at (b) $9 \mathrm{~kW}$, (c) $11 \mathrm{~kW}$, and (d) $15 \mathrm{~kW}$ 


\section{Evaluation of spheroidized tungsten carbide powder produced by induction plasma melting}

\begin{tabular}{|c|c|c|c|c|c|}
\hline $\begin{array}{l}\text { Plasma plate power } \\
\text { (kW) }\end{array}$ & $\begin{array}{c}\text { Spherical particles } \\
\text { number }\end{array}$ & $\begin{array}{l}\text { Irregular particles } \\
\text { number }\end{array}$ & $\begin{array}{l}\text { Spheroidization } \\
\text { ratio (\%) }\end{array}$ & $\begin{array}{l}\text { Fraction of evaporation } \\
(\%)\end{array}$ & $\begin{array}{l}\text { Powder density } \\
\qquad\left(\mathrm{g} / \mathrm{cm}^{3}\right)\end{array}$ \\
\hline As received & 67 & 648 & 9.4 & - & 16.414 \\
\hline 9 & 12 & 233 & 4.9 & 2.67 & 16.756 \\
\hline 11 & 582 & 51 & 91.9 & 3.19 & 16.750 \\
\hline 15 & 922 & 59 & 94.0 & 0.90 & 16.743 \\
\hline
\end{tabular}

The quantified changes in particle morphology as determined by image processing, as well as the fraction of evaporation and powder densities, are indicated in Table II. The fraction of evaporation for all experiments was low $(<4 \%)$, which can be attributed to the high boiling point $\left(6000^{\circ} \mathrm{C}\right)$ of tungsten carbide (Gignard, 1998). The densities of the plasma-treated powders were slightly higher than the feed powder due to densification of the particles through melting and void elimination, but also due to possible loss of carbon and conversion of WC to $\mathrm{W}_{2} \mathrm{C}$. The spheroidization ratio of the feed powder was $9.4 \%$, indicating that some of the irregularly-shaped particles in the feed had satisfied the selected circularity value of 0.85 for spherical particles. The treatment at $9 \mathrm{~kW}$ resulted in a decreased spheroidization ratio. In this instance, melting of the particle surfaces, partial melting of the particles, and sintering of fine and larger particles occurred. Once these particles exit the plasma tail flame, rapid quenching of the oval and sintered particles occurs, resulting in a decreased spheroidization ratio compared to the feed powder. The sintering of fine and larger particles resulted in an overall increase in particle size, shown in Figure 3 and Table III. A bimodal PSD was observed after treatment at $9 \mathrm{~kW}$, resulting in an increased mean and median compared to the feed and other plasma-treated powders. The feed powder had a unimodal distribution with a median of $58 \mu \mathrm{m}$, while the medians of the powder treated at $11 \mathrm{~kW}$ and $15 \mathrm{~kW}$ shifted slightly to a smaller particle size due to the spheroidization of the particles. The appearance of another, less significant, peak for both the 11 $\mathrm{kW}$ and $15 \mathrm{~kW}$ treatments might be due to the measurement of finer particles which affect the tail of the distribution.

The spheroidization ratios obtained after treatment of the powder at $11 \mathrm{~kW}$ and $15 \mathrm{~kW}$ were $91.9 \%$ and $94.0 \%$ respectively. A minimum energy transfer per unit time was required, which results in the melting of powder at a given powder feed rate, given by Equation [2]:

$$
P=\dot{\mathrm{m}}\left[c_{p}\left(T_{m}-T_{0}\right)+H_{m}\right]
$$

where $P$ is the minimum energy per unit time required $(\mathrm{W}), \dot{\mathrm{m}}$ is the powder feed rate $(\mathrm{g} / \mathrm{s}), c_{p}$ is the specific heat capacity $(\mathrm{J} / \mathrm{K} . \mathrm{g})$, $T_{m}$ is the melting point, $T_{0}$ is the room temperature $(\mathrm{K})$, and $H_{m}$ is the latent heat of fusion (J/g) (Jiang, and Boulos, 2006) of the powder. Therefore, for a given power input, a specific number of particles will be melted. When more power is applied, more particles can be spheroidized, as shown in Table II. This is due to the higher temperature of the plasma. The plasma, however, has a temperature profile and therefore some particles moving through the high-temperature regions will be spheroidized, while other particles might only be partially melted and do not completely spheroidize.
Increasing the $\mathrm{H}_{2}$ concentration will also influence the spheroidization ratio. The thermal conductivity of Ar is much lower than that of $\mathrm{H}_{2}-71 \mathrm{~mW} / \mathrm{m} . \mathrm{K}$ at $2100 \mathrm{~K}$ (Chen and Saxena, 1975) compared with $1178 \mathrm{~m} . \mathrm{W} / \mathrm{m} . \mathrm{K}$ for $\mathrm{H}_{2}$ (Blais and Mann, 1960). This results in more effective heat transfer from the plasma to the particles when using $\mathrm{H}_{2}$.

\section{Phase composition}

The XRD spectra of the tungsten carbide powders before and after the RF plasma spheroidization are shown in Figure 4. There are eight major diffraction peaks with $2 \theta$ values of $39^{\circ}$, $47^{\circ}, 51^{\circ}, 61^{\circ}, 69^{\circ}, 74^{\circ}, 106^{\circ}$, and $111^{\circ}$. These results conform to diffraction peaks of standard tungsten carbide powder with a body-centred cubic (bcc) lattice structure. There were two phases which were identified in all samples; $\mathrm{WC}$ and $\mathrm{W}_{2} \mathrm{C}$. A minor peak at $80^{\circ}$ indicated the presence of $\mathrm{Co}$, which is added as a binder in the tungsten carbide powder. Table IV shows that the feed powder comprised both $\mathrm{WC}$ and $\mathrm{W}_{2} \mathrm{C}$ phases. The amount of $\mathrm{W}_{2} \mathrm{C}$ phase increased with plasma plate power and with increased $\mathrm{H}_{2}$ concentration. According to Gignard (1998), the calculated equilibrium composition of the $\mathrm{C}-\mathrm{H}-\mathrm{W}$ system shows that $\mathrm{W}_{2} \mathrm{C}$ is

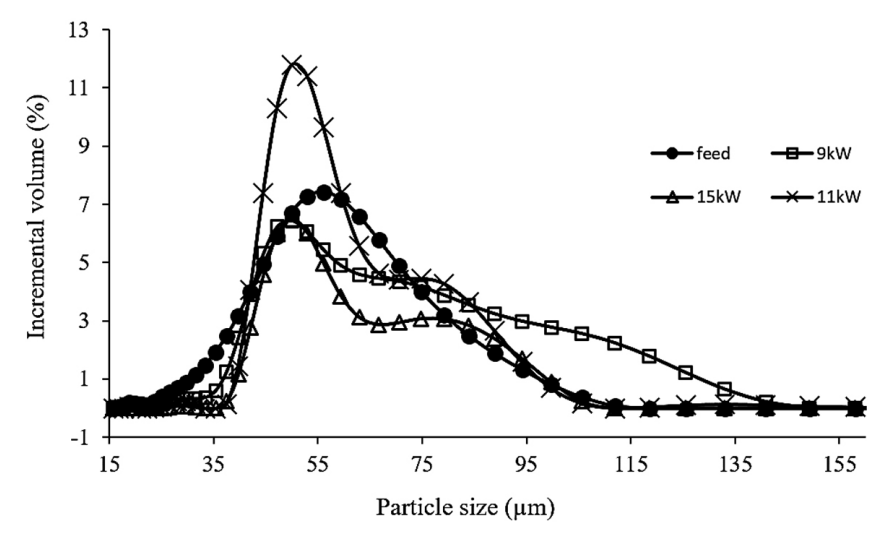

Figure 3-Incremental volume percentage as a function of particle size for tungsten carbide feed powder treated at $9 \mathrm{~kW}, 11 \mathrm{~kW}$, and $15 \mathrm{~kW}$

\section{Table III}

PSD of all powders as determined by light scattering analysis

\begin{tabular}{|l|c|c|c|c|}
\hline Sample & $\begin{array}{c}\mathbf{H}_{2} \\
(\% \mathbf{v} / \mathbf{v})\end{array}$ & $\begin{array}{c}\text { Mean } \\
(\boldsymbol{\mu m})\end{array}$ & $\begin{array}{c}\text { Median }\left(\boldsymbol{d}_{50}\right) \\
(\mu \mathrm{m})\end{array}$ & $\begin{array}{c}\text { Standard deviation } \\
(\mu \mathrm{m})\end{array}$ \\
\hline Feed & - & 62.597 & 58.222 & 1.012 \\
$9 \mathrm{~kW}$ & 0.00 & 70.115 & 62.752 & 0.946 \\
$11 \mathrm{~kW}$ & 0.04 & 74.270 & 55.156 & 0.172 \\
$15 \mathrm{~kW}$ & 0.08 & 75.958 & 53.359 & 0.187 \\
\hline
\end{tabular}




\section{Evaluation of spheroidized tungsten carbide powder produced by induction plasma melting}

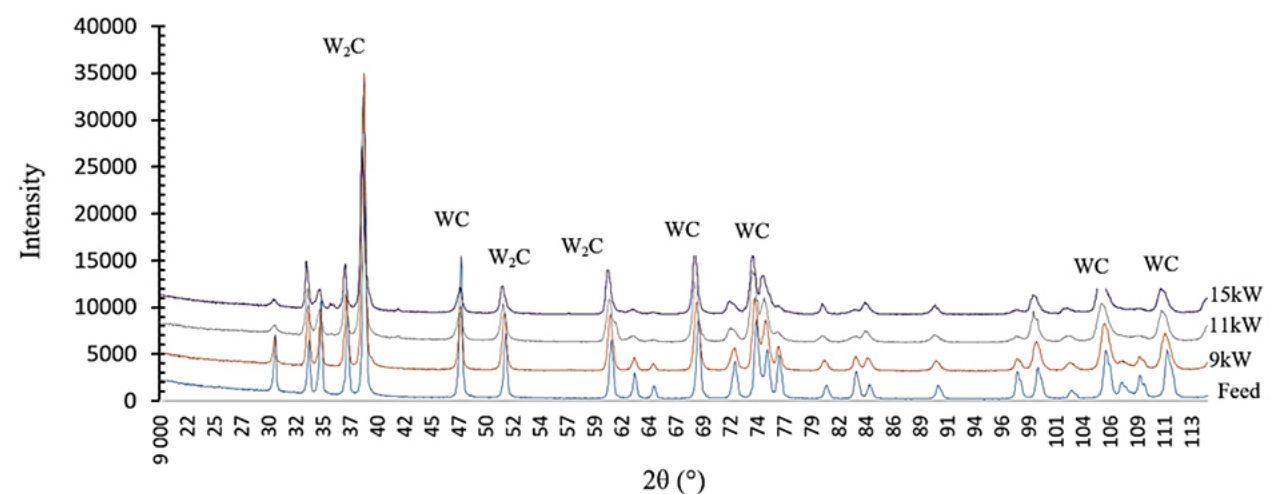

Figure 4-XRD spectra of the tungsten carbide feed and plasma-treated powders

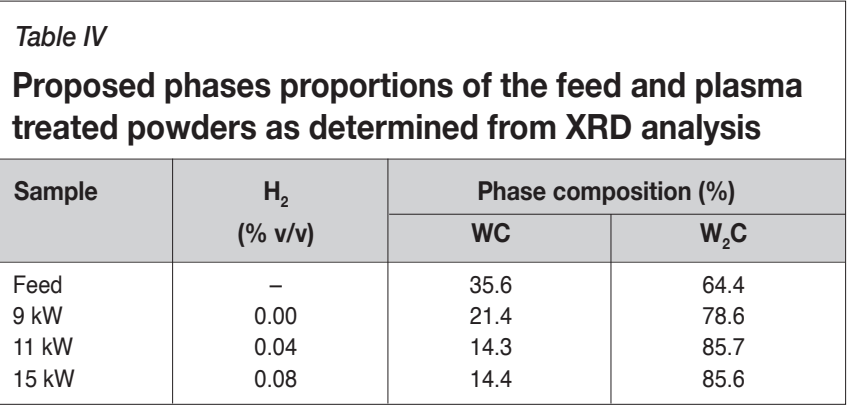

more stable at higher temperatures than WC. This explains why a fraction of the WC converted to $\mathrm{W}_{2} \mathrm{C}$ during the spheroidization process and the $\mathrm{W}_{2} \mathrm{C}$ fraction increased with increasing plasma temperature.

\section{Conclusion}

Tungsten carbide powder was successfully spheroidized utilizing an inductively coupled radio-frequency plasma process, using a reactor power greater than $9 \mathrm{~kW}$ with the addition of $\mathrm{H}_{2}$ to the sheath gas. Spheroidization increased the density of the powder. Spheroidization ratios greater than $90 \%$ were achieved at $11 \mathrm{~kW}$ and higher, with minimal powder evaporation occurring.

The XRD results showed increased proportions of $\mathrm{W}_{2} \mathrm{C}$ when the power of the RF plasma was increased. Thus the power of the plasma had a direct influence on the formation of the $\mathrm{W}_{2} \mathrm{C}$ phase due to the reduction in WC content. The $\mathrm{W}_{2} \mathrm{C}$ proportion increased with plasma plate power and with increasing $\mathrm{H}_{2}$ concentration in the sheath gas. An increase in the $\mathrm{W}_{2} \mathrm{C}$ phase at higher plasma temperatures was due to the fact that $\mathrm{W}_{2} \mathrm{C}$ is more stable than WC at higher temperatures, as confirmed by the calculated equilibrium composition of the C-H-W system (Gignard, 1998).

\section{Acknowledgements}

The authors would like to acknowledge the Nuclear Materials Development Network (NMDN) of the Advanced Materials Initiative (AMI), funded by the Department of Science and Innovation (DSI), for the financial support in conducting this study. The South African Nuclear Energy Corporation (Necsa) is acknowledged for their financial support. The following Necsa personnel are thanked for their contributions, S.J. Lotter and T.P. Ntsoane for the SEM and XRD analysis respectively, and M.M. Makhofane and P.C. Smith for the plasma experiments. M. Theron from the CSIR National Laser Centre is also thanked for supplying the tungsten carbide powder which was used for experiments.

\section{References}

JiAnG, X.L. and Boulos, M. 2006. Induction plasma spheroidization of tungsten and molybdenum powders. Transactions of Nonferrous Metals Society of China, vol.16. pp. 13-17.

Lu, X., ZHu, L., and Zhang, B. 2012. Simulation of flow field and particle trajectory of radio frequency inductively coupled plasma spheroidization. Computationalr Materials Science, vol. 65. pp. 13-18.

Barker, J., Swoyer, M, and SAIdI, J. 2003. A carbothermal reduction method for the preparation of electroactive materials for lithium ion applications. Journal of the Electrochemical Society, vol. 150, no. 6. doi: 10.1149/1.1568936

Blais, N.C. and Mann, J.B. 1960. Thermal conductivity of helium and hydrogen at high temperatures. Journal of Chemical Physics, vol. 32. pp. 1459-1465.

CHEN, S.H.P. and SAXENA, S.C. 1975. Thermal conductivity of argon in the temperature range 350 to 2500 K. Molecular Physics, vol. 29. pp. 455-466.

DevečErski, A. 2011. SiC synthesis using domestic resources. Process and Application of Ceramics, vol. 5. pp. 63-67.

Earnshaw, N. and Greenwood, A. 1997. Chemistry of the Elements. ButterworthHeinemann, Oxford. p. 308

GIGNARD, N.M. 1998. Experimental optimization of the spheroidization of metallic and ceramic powders with induction plasma. Thesis. National Library of Canada, Sherbrooke, Quebec, Canada.

Guo, M and Leu, N. 2013. Additive manufacturing: technology applications and research needs. Frontiers of Mechanical Engineering, vol. 8, no. 3 . pp. 215-243.

Haehn, R., Luederitz, E., Sattelberger, S., and Retelsdorf, H. 1986. New process for the production of cast tungsten carbide. Metal Powder Report, vol. 41, no.12. pp. 887-890.

HAynes W. 2011. CRC Handbook of Chemistry and Physics. CRC Press, Boca Raton, FL. p. 496.

HilleRT, M. 1962. The formation of pearlite. Proceedings of Decomposition of Austenite by Diffusional Processes. Philadelphia, Pennsylvania, 19 October, 1960. Zackay, V.F. and Aaronson, H.I. (eds.). Interscience Publishers, New York, 1962. pp. 197-249.

Ku, N., Pittari, J.J., Kilczewski, S., and Kudzal, A. 2019. Additive manufacturing of cemented tungsten carbide with a cobalt-free alloy binder by selective laser melting for high hardness applications. JOM, vol. 71, no. 4. pp. 1535-1542.

KWAK, S. 2010. A review of switch mode sustain drivers with resonant networks for plasma display panels. IEEE Transactions on Industrial Electronics, vol. 57, no. 5. pp. 1624-1634.

Pohanish, R. 2012. Sittig's Handbook of Toxic and Hazardous Chemicals and Carcinogens. (6th edn). Elsevier, Norwich. p. 2670.

Tong, J. 2015. Fabrication of micro-fine spherical high Nb containing TiAl alloy powder based on reaction synthesis and RF plasma spheroidization. Powder Technology, vol. 28. pp. 9-15. 